\title{
Family medicine faces shortage of doctors willing to teach
}

\author{
Cite as: CMAJ 2018 May 28;190:E666. doi: 10.1503/cmaj.109-5604
}

Posted on cmajnews.com on May 10, 2018.

t's t's increasingly difficult for medical students to gain clinical experience in family medicine because there aren't enough physicians willing to supervise clerkships and electives.

The demand for family medicine electives has "gone up an absolutely crazy amount" with increasing medical school enrollment, says Dr. Keyna Bracken, director of McMaster University's family medicine clerkship program. However, the number of physicians who are willing to teach "hasn't gone up exponentially the same amount."

Tougher competition for residency positions is compounding the problem, she explains. "As students become more anxious about this, they apply more broadly and they look to have elective experiences all over the place."

Only $45 \%$ of medical students were offered their first-choice elective in family medicine in 2016-2017, according to the Association of Faculties of Medicine of Canada. That's 13\% lower than the average success rate across specialties.

With not enough family medicine preceptors to go around, some students are taking electives in complementary specialties instead. "You see a lot of physicians in primary care whose students do electives in dermatology or cardiology," says Celine Conforti, a third year medical student at McMaster.

Some family doctors are simply too burned out to teach, says Dr. Jason Profetto, an assistant clinical professor at McMaster. "Teaching medical students is becoming lower and lower on their priority list."

Profetto says that pushing these physicians to supervise students isn't a solution to the preceptor shortage. "If you get

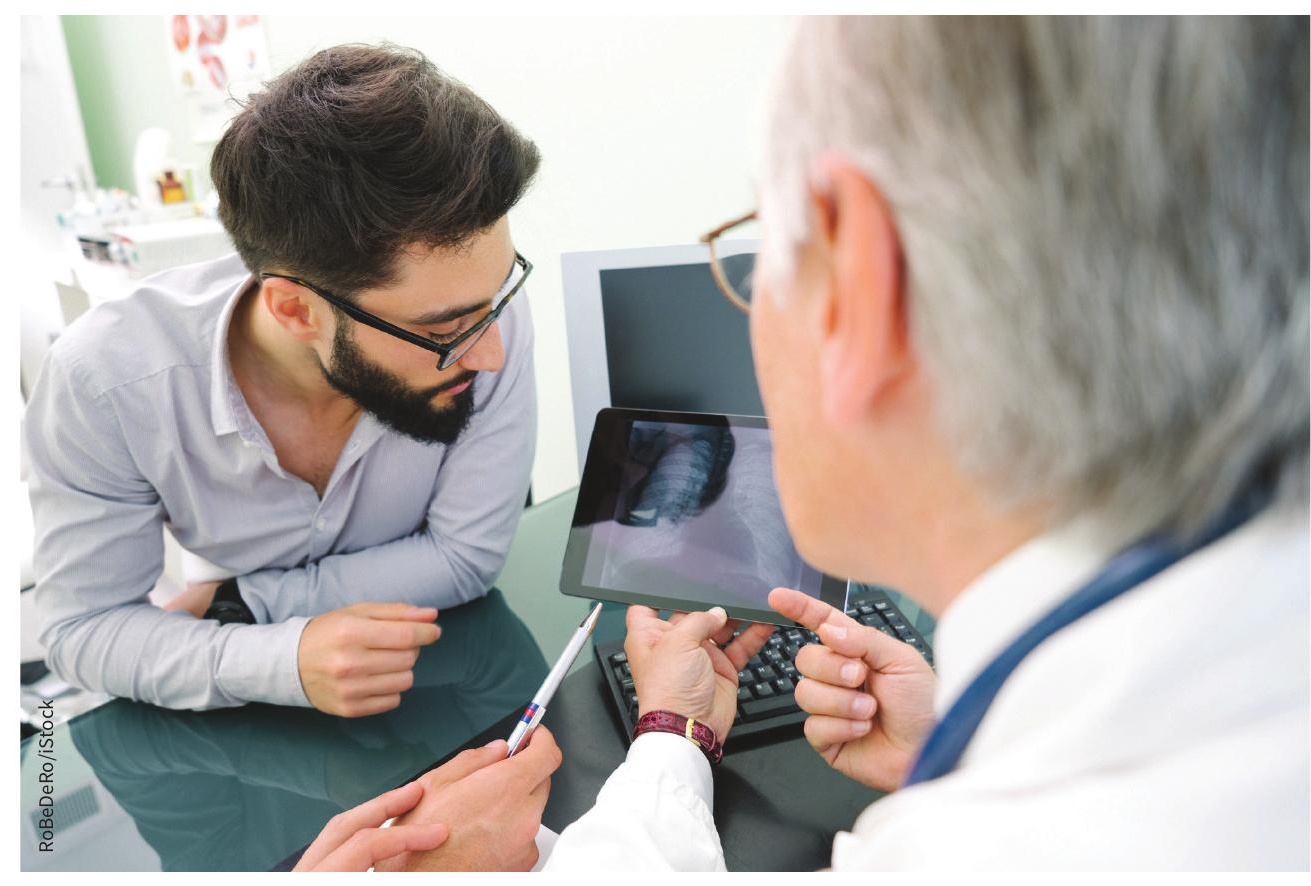

Not enough family doctors want to supervise medical students, say educators.

doctors that are teaching and aren't super keen to do it, you can perpetuate a sort of burned-out feeling in family medicine."

Other physicians worry they will have to slow down and see fewer patients if they become a preceptor, and there are no monetary incentives to offset that burden. There's also a common misconception that patients will be uncomfortable with the presence of medical students.

In a recent study presented at the Canadian Conference on Medical Education, Profetto found that more than $80 \%$ of patients are comfortable with medical students being involved in their care, with the exception of intimate exams. Seventy percent of patients agreed that medical students improve the delivery of care at their family physician's office.
Lack of confidence is another major barrier to doctors taking on students, says Dr. Kymm Feldman, former undergraduate director of family medicine at the University of Toronto. "You can have selfconfidence as a clinician, but teaching is a whole different set of skills."

Feldman oversaw the university's largest preceptor recruitment period in recent years. The school launched extensive continuing medical education and faculty development to help physicians build their skills and confidence as teachers.

Retention is another part of the puzzle, she says. "We developed a detailed awards process and really recognized those people who had excellent evaluations and made sure they wanted to continue teaching."

Caroline Mercer, CMAJ 